\title{
One-Pot Cascade Reactions Catalyzed by Star Polymer Catalysts
}

Key words

star polymer catalysts

cascade reaction

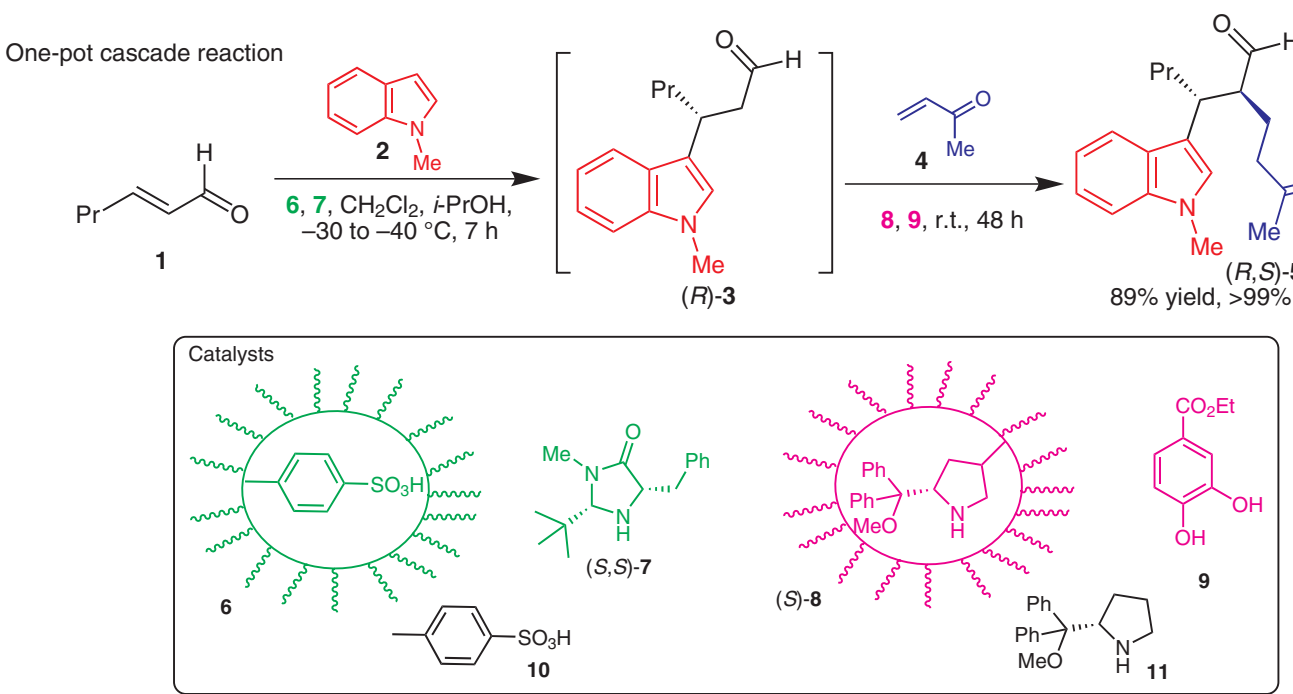

Preparation of acidic star polymer 6<smiles>CC(C)C(c1ccccc1)N(OC(C)C(C)(C)C)C(C)C(C)(C)C</smiles>

12<smiles>C=Cc1ccccc1</smiles>

13<smiles>C=Cc1ccccc1</smiles>

14

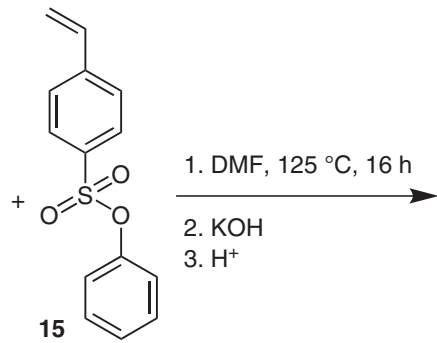

2. $\mathrm{KOH}$ 3. $\mathrm{H}^{+}$

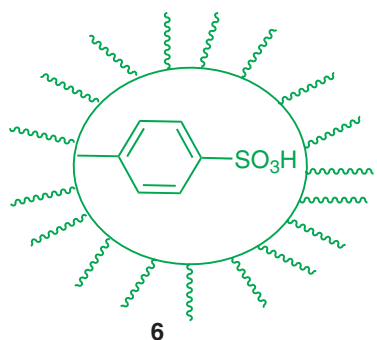

Significance: Non-interpenetrating two star polymer catalysts designed to mimic the site isolation characteristics of enzymes enabled a one-pot asymmetric cascade reaction. Thus, the one-pot nucleophilic addition of $\mathbf{2}$ to $\mathbf{1}$ and Michael addition of the resulting $\mathbf{3}$ to $\mathbf{4}$ were performed with a star polymer salt catalyst $\mathbf{6 \cdot 7}$ (20 mol\%) [prepared from an acidic star polymer $\mathbf{6}$ and imidazolidinone (S,S)-7], a pyrrolidine star polymer (S)-8 (20 mol\%), and a catechol mediator $\mathbf{9}$ (1 mol equiv) to give $(R, S)-\mathbf{5}$ in $89 \%$ yield with $>99 \%$ ee and $96 \%$ de. The use of $\mathbf{1 0}$ or $\mathbf{1 1}$ in place of $\mathbf{6}$ or $\mathbf{8}$ under similar conditions did not give $\mathbf{5}$.

sYNFacts Contributors: Yasuhiro Uozumi, Yoichi M. A. Yamada, Toshihiro Watanabe Synfacts 2008, 8, 0883-0883 Published online: 23.07.2008 DOI: 10.1055/s-2008-1077922; Reg-No.: Y06808SF
Comment: The acidic star polymer 6 was prepared from polystyrene macroinitiator $\mathbf{1 2}$, styrene 13, divinylbenzene $\mathbf{1 4}$ and phenyl $p$-styrenesulfonate $\mathbf{1 5}$ according to their previous report (Angew. Chem. Int. Ed. 2005, 44, 6384). The amine star polymer $\mathbf{8}$ was prepared via a similar procedure. Polystyrene macroinitiator 12 was developed by Hawker and co-workers (J. Am. Chem. Soc. 1999, 121, 3904). When imidazolidinone $(S, S)-\mathbf{7}$ was replaced with its enantiomer $(R, R)-\mathbf{7}$, a diastereomer $(S, S)-\mathbf{5}$ was obtained in $80 \%$ yield with $>99 \%$ ee and $96 \%$ de. 